\title{
EVALUATION OF APOPTOGENIC EFFECTS OF AVERRHOA BILIMBI EXTRACT ON EHRLICH ASCITES CARCINOMA BEARING MICE
}

\author{
JYOTI B CHAUHAN ${ }^{1}$, BALAJI KS ${ }^{2}$, JAYARAMA $S^{2}$, WETHROE KAPFO ${ }^{3 *}$ \\ ${ }^{1}$ Department of Studies in Biotechnology, Microbiology and Biochemistry, Pooja Bhagavat Memorial Mahajana Education Centre, \\ PG Wing of SBRR Mahajana First Grade College, Metagalli, Mysore, Karnataka, India. ${ }^{2}$ Department of Biotechnology, Teresian College, \\ Siddhartha Layout, Mysore, Karnataka, India. ${ }^{3}$ Department of Biochemistry, PRIST University, Vallam, Thanjavur, Tamil Nadu, India. \\ Email: kapfo88@gmail.com
}

Received: 02 August 2016, Revised and Accepted: 19 September 2016

\section{ABSTRACT}

Objective: The proapoptotic potential of aqueous methanol extract of Averrhoa bilimbi fruit (AMBE) in vivo against Ehrlich ascites carcinoma (EAC) bearing Swiss albino mice was studied.

Methods: Cytotoxicity of the extract on the EAC cells was monitored by tumor growth response, trypan blue exclusion assay, Giemsa staining, DNA fragmentation, fluorescence-activated cell sorting (FACS) analysis, and reverse transcription-polymerase chain reaction (RT-PCR). The phytochemical screening using LC-MS and Fourier transform infrared (FT-IR) was conducted.

Results: The extract at $100 \mathrm{mg} / \mathrm{kg}$ body weight was significantly cytotoxic toward the cells with approximately $73 \%$ growth inhibition on day 12 . It markedly decreased the tumor volume by $65 \%$ and viable tumor cell by $72 \%$. Giemsa staining of AMBE treated cells displayed apoptotic morphologies such as membrane blebbing, cytoplasmic condensation, and apoptotic bodies. Cytotoxicity of the extract to the carcinoma cells through apoptosis was further highlighted by DNA fragmentation in treated cells, while FACS analysis showed that growth arrest took place at $\mathrm{G}_{0} / \mathrm{G}_{1}$ phase. RT-PCR analysis displayed reduced level of Bcl-2/Bax ratio in test cells as compared to control cells. Phytochemical analysis of the extract using LC-MS and FT-IR studies showed that protocatechuic acid was the predominant component present in the extract.

Conclusion: Our studies indicated that Averrhoa bilimbi extract expressed significant apoptogenic potential against EAC cells in vivo.

Keywords: Ehrlich ascites carcinoma, Apoptosis, Fluorescence-activated cell sorting, Bax/Bcl-2, Protocatechuic acid.

(C) 2016 The Authors. Published by Innovare Academic Sciences Pvt Ltd. This is an open access article under the CC BY license (http://creativecommons. org/licenses/by/4. 0/) DOI: http://dx.doi.org/10.22159/ajpcr.2016.v9s3.14438

\section{INTRODUCTION}

As cancer continues to pose as one of the deadliest diseases in the world, reports of the negative side effects of synthetic anticancer drugs have paved to vigorous investigations of novel drug discoveries from natural resources and the phytochemical mode of action against various cancers due to their low toxicity [1]. One well-recognized pathway is apoptosis, which is a mode of cell death used by multi-cellular organisms to eradicate cells in diverse physiological and pathological settings [2]. Apoptosis is a genetically controlled process that creates a balance between proliferation and cell death to maintain physiological homeostasis in tissues [3,4]. Disturbance in the homeostasis enables cells to escape apoptosis resulting in uncontrolled cell proliferation Human malignancies occur fundamentally as a result of inhibition of apoptosis transforming cells with harmful genetic defects to fatal immortal colonies of cells called tumors $[5,6]$. This is because apoptosis is associated with a number of independently yet synergistically acting genes that encode pro- and anti-apoptotic proteins. Extensive studies supporting the key role of Bcl-2 family in promoting or inhibiting intrinsic apoptotic pathway through mitochondrial dysfunction have been reported $[7,8]$. Bax and $\mathrm{Bcl}-2$ are the major pro- and anti-apoptotic members of Bcl-2 family wherein Bax stimulates permeabilization of mitochondrial outer membrane in response to different cellular stresses leading to cell death and Bcl-2 inhibits the activity of Bax preventing apoptosis [8,9]. Thus, overexpression of Bax due to various external agents enhances apoptosis even among proliferating cells at any stage of cell cycle $[10,3]$. With this context, it is noteworthy that our investigation focuses on apoptosis- inducing ability of Averrhoa bilimbi extract (AMBE) on Ehrlich ascites carcinoma cells (EAC), which is one of the most common experimental tumors, as a primary factor in considering its efficacy as chemopreventive agent. Averrhoa bilimbi L.
(Oxalidaceae) is a fruit tree that has folkloric implications against many ailments and diseases. Although a native of Malaysia and Indonesia, it is a widely cultivated tree in southern India, particularly in Mangalore and Udupi. Commonly known as bilimbi, the oblong very sour fruits are eaten fresh and also used in production of vinegar, wine, pickles, jams, and jellies. Bilimbi has been widely used as traditional medicine to treat a cough, cold, itches, boils, rheumatism, syphilis, diabetes, and whooping cough. Experimental pharmacological studies have shown that the fruit alleviates hypertension [11]. Aqueous extract of fresh bilimbi has shown to exhibit low antioxidant activities and low nitric oxide inhibition activity [12]. Our previous studies, however, showed the significant antioxidant potential of the AMBE [13]. Our present investigation, thus, aims to determine the pro-apoptotic potential of bilimbi extract and to understand underlying mechanism which induces apoptosis in murine carcinoma model.

\section{METHODS}

\section{Chemicals}

Dimethyl sulfoxide was obtained from MERCK Limited, Mumbai, India Agarose was procured from Genei while trypan blue, Giemsa stain ethidium bromide were obtained from Himedia, India.

\section{Animals}

Swiss albino mice (6-8 weeks old) were obtained from JSS college of Pharmacy, Mysore. Male Swiss albino mice (28-30 g) maintained on standard laboratory diet, having free access to tap water, were tested in this study. The animals were housed in the departmental animal house and exposed to 12 hrs cycle of light and dark. All the procedures described were conducted with written approval obtained from the local ethical committee Farooqia College of Pharmacy, Mysore, India. 


\section{Plant materials}

Fresh fruits of Averrhoa bilimbi L. (1.0 kg) were collected from Udupi, Karnataka, India, between April and July, thoroughly cleaned with distilled water, deseeded, blended and extracted using $1 \mathrm{l}$ of $60 \%$ methanol/water for $3 \mathrm{hrs}$ at $40^{\circ} \mathrm{C}$ under continuous agitation. After filtration using muslin cloth, the residue was reextracted using $1 \mathrm{l}$ of the same extract solvent. The filtrates were pooled and concentrated using a rotary evaporator (Buchi, Germany). The aqueous portion was dried in a hot-air oven at $50^{\circ} \mathrm{C}$ giving the crude AMBE for subsequent experimentation.

\section{Experimental design}

EAC cells were maintained in the peritoneal cavity of female Swiss albino mice as described previously [14]. The 8-10 days old ascitic tumor from animals was collected by aspirating the ascitic fluid in sterile isotonic saline. The viable EAC cells were counted using trypan blue indicator and injected $\left(1 \times 10^{5} \mathrm{EAC}\right)$ intraperitoneally into male Swiss albino mice weighing 18-22 g on day 0 followed by a day of incubation which allowed multiplication of the cells. On day 1 , the animals were randomized and grouped $(n=6)$ into Group I, Control (Untreated) and Group II, extract treated. Test groups were administered with plant extract of concentration $100 \mathrm{mg} / \mathrm{kg}$ body weight prepared in DMSO through intraperitoneal injection. The treatment of mice was conducted at intervals of $24 \mathrm{hrs}$ from day 5 to day 11 . The animals were euthanized on day 12 by cervical dislocation followed by assessment of tumor volume and tumor cell count.

\section{Tumor growth response}

The antitumor effect of AMBE was analyzed by change in body weight, ascites tumor volume, viable tumor cell count, and percentage tumor inhibition $[15,16]$.

The tumor growth inhibition was calculated using the following formula:

$\%$ tumor inhibition $=(1-$ Average number of cells in test group $/$ average number of cells in control group) $\times 100$.

\section{Apoptotical morphology and DNA fragmentation}

The cytoplasmic morphology of the control and test cells was assessed using Giemsa stain. DNA fragmentation was analyzed by running the genomic DNA extracted from EAC cells of control and treated mice on agarose gel electrophoresis [17].

Detection of apoptosis using fluorescence-activated cell sorting (FACS) analysis

To detect the apoptotic effect of AMBE flow cytometry analysis on control and treated cells was conducted using the protocol previously reported [18].

RNA isolation and reverse transcription-polymerase chain reaction (RT-PCR)

Total RNA from control and test sample was prepared using the Trizol reagent (Invitrogen) and was used for RT-PCR using the Super-Script III One-Step RT-PCR system (Invitrogen) according to the manufacturer's protocol. We used $1 \mu \mathrm{g}$ of RNA for RT-PCR using the Super-Script III One-Step RT-PCR system (Invitrogen Life Technologies). Briefly, the complementary DNAs were synthesized at $50^{\circ} \mathrm{C}$ for 30 minutes followed by incubation at $94^{\circ} \mathrm{C}$ for 2 minutes. Subsequently, 30 cycles of PCR were carried out with denaturation at $94^{\circ} \mathrm{C}$ for 45 seconds, annealing at $53^{\circ} \mathrm{C}$ for 45 seconds, and extension at $72^{\circ} \mathrm{C}$ for 1.5 minutes, followed by a final incubation at $72^{\circ} \mathrm{C}$ for 7 minutes. For amplifying Bax and Bcl- 2, the following primers sets (Sigma) were used. Bax PCR primers set (Product No. B8304) Reverse primer sequence (3' antisense): 5'-CAT CTT CTT CCA GAT GGT GA-3' Forward primer sequence (5' sense): 5'GTT TCA TCC AGG ATC GAG CAG-3' and bcl-2 PCR primers set (Product No. B9179) Reverse primer sequence (3' antisense): 5'- GAG ACA GCC AGG AGA AAT CA-3' Forward primer sequence (5' sense): 5'- CCT GTG GAT GAC TGA GTA CC-3'. GAPDH (Product No. P7732) Reverse primer sequence (3' antisense): 5'- YGC CTG CTT CAC CAC CTT C-3' Forward primer sequence (5' sense): 5'- TGC MTC CTG CAC CAC CAA CT-3' where $\mathrm{M}=\mathrm{A}$ or $\mathrm{C} \mathrm{Y}=\mathrm{T}$ or $\mathrm{C}$ that was used as a loading control was amplified using primers that have been previously published and it served as a loading control. [19]. The PCR products were then separated on a $1.5 \%$ agarose gel, and results were documented.

High performance liquid chromatography (HPLC)-Electrospray ionization-mass spectrometry (ESI-MS) analyses

The Thermo LCQ Deca XP MAX ion trap mass spectrometer (USA) with software Xcalibur equipped with ThermoFinnigan Surveyor HPLC was used to separate and identify the probable bioactive compounds present in AMBE. The heated capillary and spray voltage were maintained at a temperature of $275^{\circ} \mathrm{C}$ and $4.5 \mathrm{kV}$. Nitrogen is operated at $40 \mathrm{psi}$ for sheath gas flow rate and $26 \mathrm{psi}$ for auxiliary/sheath gas flow rate. The full scan mass spectra from m/z 50-2000 were acquired in positive ion mode with a scan speed of 1 second per scan. The mass spectrometry was performed using helium as collision gas, operated at 0.1 mtorr.

Chromatographic separations were done using a BDS HYPERSIL C-18 column $(250 \times 4.6 \mathrm{~mm}, 5 \mu \mathrm{m}$ particle size $)$ equipped with PDA/UV detector with $280 \mathrm{~nm}$ as the detecting wavelength in room temperature $\left(27^{\circ} \mathrm{C}\right)$ under the following conditions: $200 \mu \mathrm{l}$ minute ${ }^{-1}$; solvent $\mathrm{A}$, methanol; solvent $\mathrm{B}, 0.1 \%$ formic acid in water starting from 0 to 20 minutes (40-52\% A), 20-40 minutes (52-80\% A), and 40-60 minutes (80\% A).

\section{Fourier transform infrared spectroscopy}

FT-IR spectra were recorded in $\mathrm{KBr}$ pellet on a Jasco FTIR- 5300 spectrometer in spectral range $400-4000 \mathrm{~cm}^{-1}$.

\section{Statistical analysis}

The data expressed as the mean \pm Standard deviation were statistically analyzed using the software Origin version 5.0.

\section{RESULTS}

\section{Cytotoxicity of AMBE}

The ability of AMBE to induce cell death and enable body weight decline of EAC bearing mice was evaluated wherein approximately $73 \%$ growth inhibition was observed on day 12 (Fig. 1 and Table 1). Tumor volume

Table 1: Reduction in ascites fluid volume and viable cell count of control and treated EAC cells

\begin{tabular}{lll}
\hline Sample & Volume of ascites fluid $(\mathbf{m l})$ & Cell count $\left(\mathbf{1 \times 1 \mathbf { 1 0 } ^ { \mathbf { 6 } } )}\right.$ \\
\hline Control & $5.37 \pm 0.265$ & $11.92 \pm 1.405$ \\
Test & $3.37 \pm 0.351$ & $3.29 \pm 0.912$ \\
\hline
\end{tabular}

EAC: Ehrlich ascites carcinoma

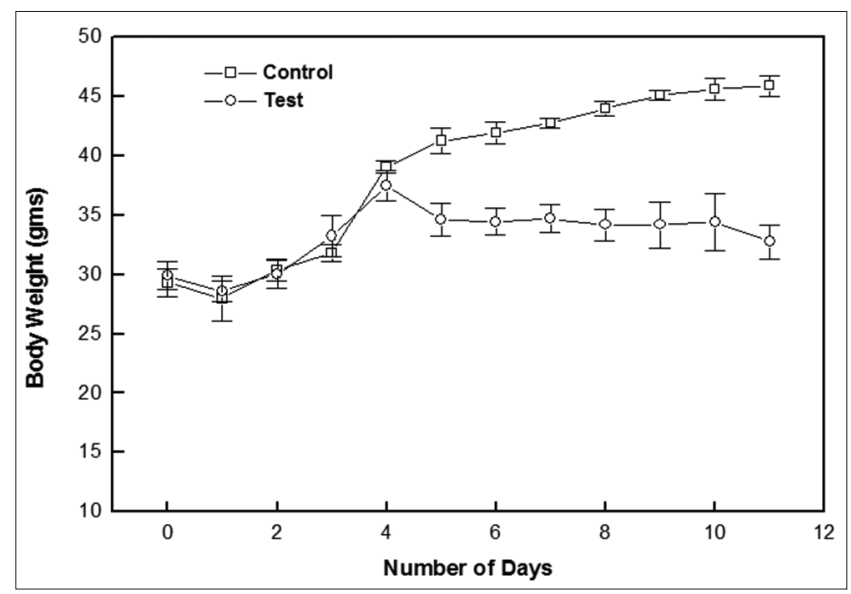

Fig. 1: The body weight in grams of untreated (control) andaqueous methanol bilimbi extract treated Ehrlich ascites carcinoma bearing mice monitored during the course of administration. Results are expressed as mean of replicates of three \pm Standard deviation. $\%$ tumor inhibition was calculated to be $73 \%$ 
of treated EAC bearing mice significantly decreased, by $65 \%$, to the tumor volume from untreated mice (Table 1).

\section{Apoptotical morphology and DNA fragmentation}

Characteristic apoptotical morphologies were observed after staining the treated cells and control with Giemsa stain. This included plasma membrane blebbing, cytoplasmic condensation, formation of apoptotic bodies, and alteration in membrane symmetry (Fig. 2). The DNA extracted from test cells bore internucleosomal fragmentation on agarose gel electrophoresis (Fig. 3).

\section{Effect of AMBE on cell cycle}

Cell death of AMBE treated EAC cells increased by $29 \%$ at $\mathrm{G}_{0} / \mathrm{G}_{1}$ phase. This indicated that growth arrest took place at $G_{0} / G_{1}$ phase in EAC cells, thus leading to AMBE induced apoptosis (Fig. 4).

\section{RT-PCR analysis}

The PCR expression profiles of Bax and Bcl-2 genes demonstrated that AMBE induced apoptosis to EAC cells, characterized by the overexpression of pro- apoptotic gene Bax and decrease in expression of anti- apoptotic gene Bcl-2 compared to the control cells (Fig. 5). Bax/Bcl-2 mRNA copy

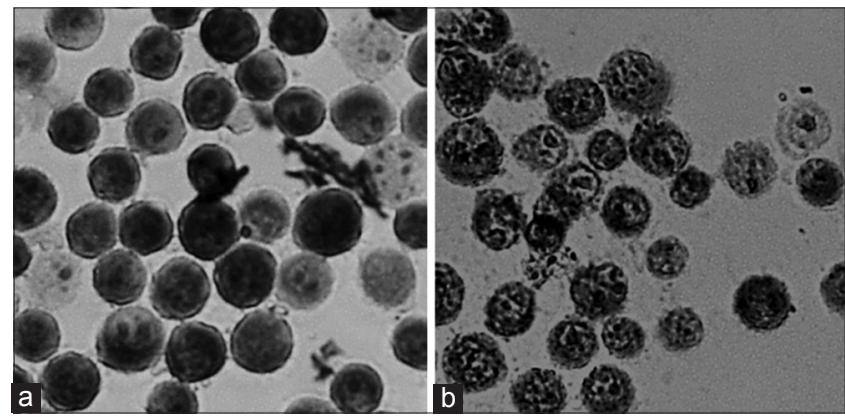

Fig. 2: Giemsa stained Ehrlich ascites carcinoma cells of

(a) Untreated (Control) mice, and (b) aqueous methanol bilimbi extract treated mice

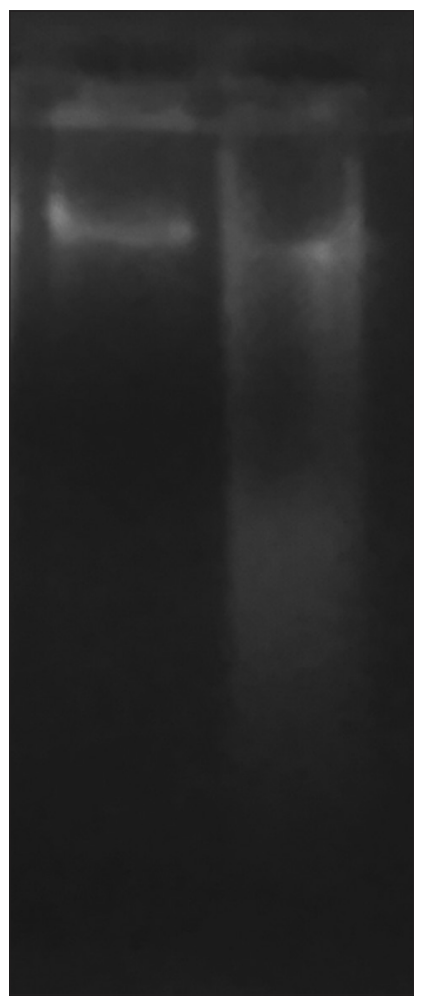

Fig. 3: Fragmentation pattern of DNA isolated from untreated and treated Ehrlich ascites carcinoma cells number ratio also called apoptotic frequency was calculated based on gene expressions both in untreated and treated EAC cells. The Bax/Bcl-2 ratio was increased in test cells when compared to control cells (Fig. 6).

Phytochemical screening using HPLC-ESI-MS

AMBE was subjected to LC- MS and FT-IR analysis to identify the prominent phytoconstituents responsible for rendering pro-apoptotic

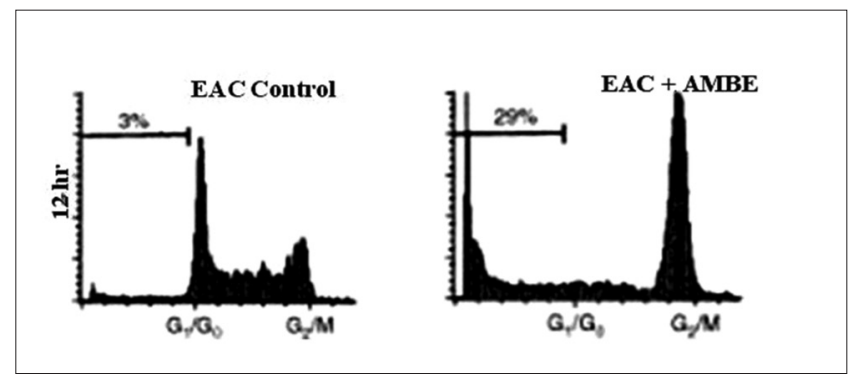

Fig. 4: Fluorescence-activated cell sorting analysis of the untreated and aqueous methanol bilimbi extract treated cells wherein growth arrest took place at $G_{0} / G_{1}$ phase

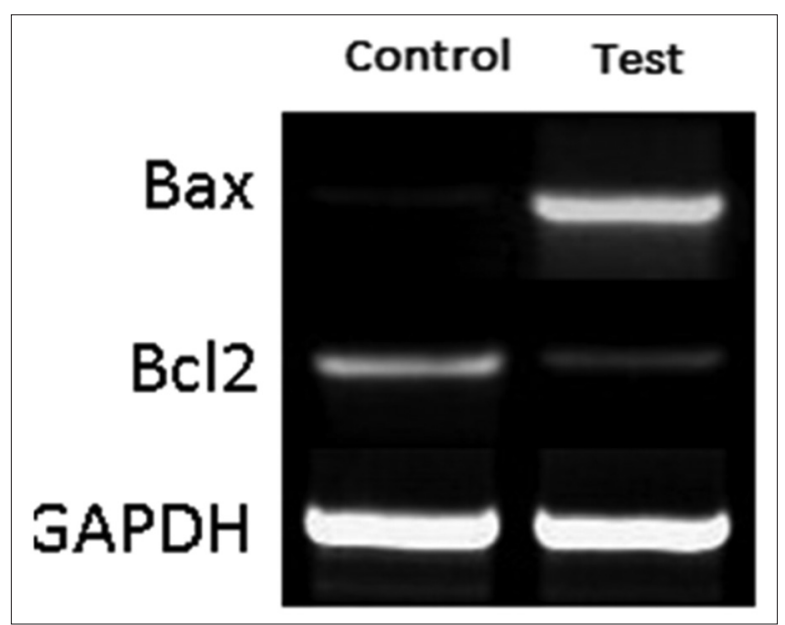

Fig. 5: Reverse transcription polymerase chain reaction of mRNA levels of Bax and Bcl-2 in Ehrlich ascites carcinoma cells treated withaqueous methanol bilimbi extract. Lane 1: Untreated (Control); Lane 2: Treated. GAPDH mRNA served as internal control. The quantitative data are means \pm standard deviation of three repeats from one independent study

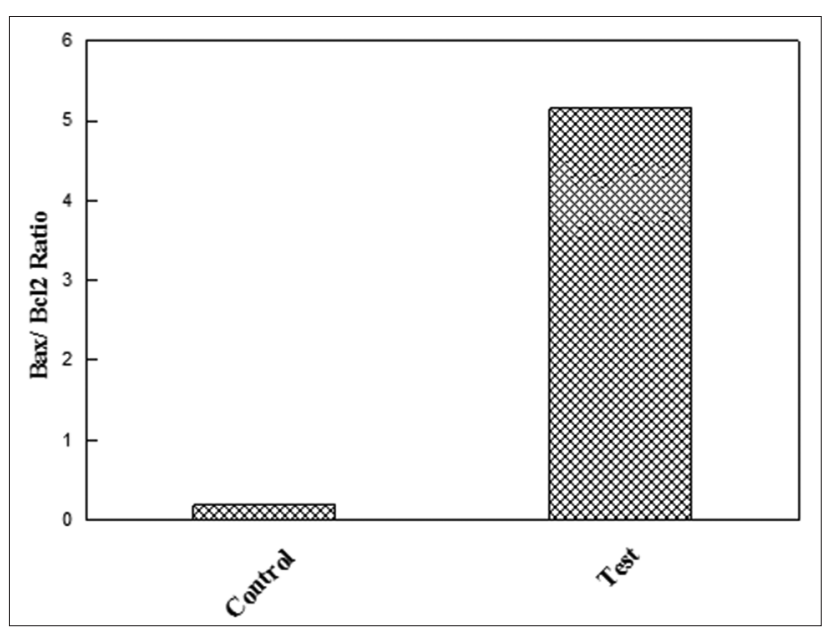

Fig. 6: Bax/Bcl-2 mRNA copy number ratio of control and treated cells after qRT- polymerase chain reaction analysis 
activity. The mass spectra obtained were compared to standard protocatechuic acid (PCA). The prominent phytochemical of molecular mass $\mathrm{m} / \mathrm{z}$ 157, eluted at 10.78 minutes (Fig. 7a), and gave characteristic fragment ion at $\mathrm{m} / \mathrm{z} 110(\mathrm{M}+\mathrm{H}-46)^{+}$due to loss of carboxyl group which correlated with the fragmentation pattern of the standard PCA (Figs. 7b and c). The Fourier transform infrared spectrum of bilimbi extract was compared to the FT-IR spectra of PCA reported in literature (Fig. 8) [16, 17]. Characteristic strong bands at $3267 \mathrm{~cm}^{-1}$ due to $\mathrm{OH}$ group, $1636 \mathrm{~cm}^{-1}$ due to $C=0$ stretch of $\alpha, \beta$ - unsaturated acid, $1457 \mathrm{~cm}^{-1}$ due to $C=C$ bond of aromatic ring, $1251 \mathrm{~cm}^{-1}$, and $1078 \mathrm{~cm}^{-1}$ were observed rendering the compound to be PCA.

\section{DISCUSSION}

One of the successful effects that lead to therapeutic value of any anticancer drug/extract is the induction of apoptosis or programmed cell death in cancer cells comprising chemotherapy and chemoprevention [20]. EAC cells are one of the most common experimental tumors used for modeling because it resembles human tumors which are undifferentiated and have rapid growth rate [21]. Ascitic fluid is the direct nutritional source for tumor cells and a rapid increase in ascitic fluid with tumor growth would be means to meet the nutritional requirements of tumor cells [22]. DNA fragmentation is one of the hallmarks of apoptosis which could be route of the extract induced apoptosis. To further understand the mechanism, cell cycle phase specificity and quantification of apoptosis through FACS was conducted wherein propidium iodide (PI) dye binds to DNA in cells at all stages of the cell cycle and the intensity with which a cell nucleus emits fluorescent light is directly proportional to its DNA content [23]. Apoptotic cells generally are hypodiploid which stainless intensely with PI thus emitting lesser fluorescence [24]. The apoptotic frequency was higher in cells of the treated mice than that of the control group. The quantitative determination of mRNA copy number established a relationship between the pro-apoptotic activity of AMBE and intracellular balance between Bcl-2 and Bax activity. Induction of Bax initiates cell death as it is responsible for the mitochondrial pathway of apoptosis [25]. Thus, AMBE-induced apoptosis was found to be associated to inhibition of Bcl-2 and Bax overexpression. The predominant phytoconstituent in AMBE was PCA which either independently or synergistically influenced gene expressions responsible for inducing apoptosis. Numerous investigations on pro-apoptotic potential of PCA (PCA) on cancer cells and their possible mechanism of action have been reported. PCA detected in rosemary extract and Egyptian propolis extract was among the bioactive compounds expressing antitumor activity against EAC cells [26]. Pro-apoptotic and anti-proliferative activity of PCA against cancers - such as colon, pancreatic, oral, and skin - cancers are extensively reported [27]. Studies on pro-apoptotic activity of Hibiscus PCA on HL- 60 cells showed that it reduced Bcl-2 protein expression and increased Bax protein expression [28]. PCA was one among the compounds contributing to the anticancer and chemopreventive properties of ethyl acetate extract of Dillenia suffruticosa which postulated its cytotoxic effect toward MCF-7 cells via mitochondrial dependent apoptosis [29]. PCA expressed apoptotic effects on human breast, lung, liver, cervix, and prostrate cancer cells as evidenced by enhanced DNA fragmentation and reduced mitochondrial membrane potential [30]. Effect of PCA on human gastric carcinoma cells at various time intervals significantly resulted in morphological alterations such as membrane blebbing, nuclear condensation, and fragmentation which are characteristic of apoptosis. Cell cycle analysis showed that PCA caused $\mathrm{G}_{1}$ and $\mathrm{G}_{2} / \mathrm{M}$ growth arrest in the gastric carcinoma cells [24]. Chemopreventive action of PCA has been demonstrated extensively in various cancer models such as pancreatic, colon, liver cell adenomas and carcinomas, tongue, glandular stomach, oral cavity, and urinary bladder of chemically induced carcinogenesis in laboratory animals. Its effect after administration was observed in the initiation phase and in the promotion/progression of carcinogenesis. Both its antiproliferative action and chemopreventive ability have been attributed largely to its



Fig. 7: (a) High performance liquid chromatography profile of bilimbi extract showing elution of protocatechuic acid (10.86 minutes) as the prominent compound, (b) Electrospray ionization mass spectra of standard protocatechuic acid, (c) Electrospray ionization mass spectra of bilimbi extract 


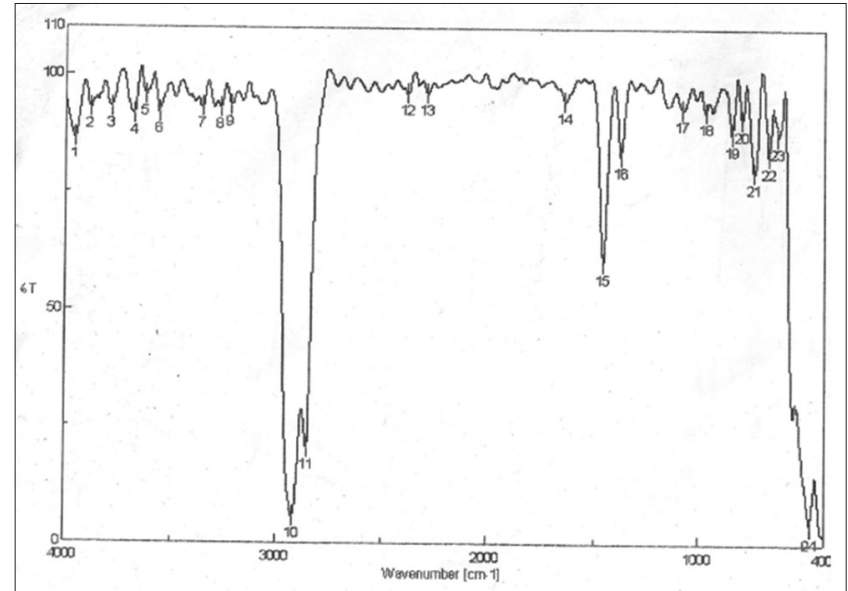

Fig. 8: Fourier transform infrared spectral analysis of the extract helped confirming the presence of protocatechuic acid by their vibrational spectra compared to those reported in literature

antioxidant properties [31].

\section{CONCLUSION}

Our primary results, thus, demonstrate the significant role AMBE has in preventing cancer from becoming malignant by inducing apoptosis of the EAC cells. AMBE may hold potential as a pharmaceutical drug and its apoptotic activities may contribute to its well- documented clinical activity since its effects includes inducing tumor cell apoptosis through increase Bax/Bcl-2 expression ratio. Our findings are the first report wherein further experimentation is being developed to establish the mechanism of action of the active principle. Purification and characterization of the active principle is under progress.

\section{ACKNOWLEDGMENT}

The authors thank the University Grants Commission, New Delhi, India for their financial support (Project F.No. 37-519 (2009) SR), the Director of Pooja Bhagavat Memorial Mahajana Education Centre, PG Wing of SBRR Mahajan First Grade College and Mahajana Education Society, Mysore, India for providing the infrastructure for conducting the experiments, Principal of Teresian College, Mysore, India for allowing the authors to conduct the in vivo experiments. Wethroe Kapfo thanks the Council for Scientific and Industrial Research, Government of India for financial support as Senior Research Fellowship (08/6/6 (0001)/2014-EMR-I).

\section{REFERENCES}

1. Kennedy DO, Wightman EL. Herbal extracts and phytochemicals: Plant secondary metabolites and the enhancement of human brain function. Adv Nutr 2011;2(1):32-50.

2. Bhattacharyya A, Choudhuri T, Pal S, Chattopadhyay S, K Datta G, $\mathrm{Sa} \mathrm{G}$, et al. Apoptogenic effects of black tea on Ehrlich's ascites carcinoma cell. Carcinogenesis 2003;24(1):75-80.

3. Denmeade SR, Isaacs JT. Programmed cell death (Apoptosis) and cancer chemotherapy. Cancer Control 1996;3:303-9.

4. Paul-Samojedny M, Kokocinska D, Samojedny A, Mazurek U, Partyka R, Lorenz Z, et al. Expression of cell survival/death genes: Bcl2 and Bax at the rate of colon cancer prognosis. Biochim Biophys Acta 2005; 1741(1-2):25-9.

5. Hanahan D, Weinberg RA. Hallmarks of cancer: The next generation. Cell 2011;144(5):646-74.

6. Khodapasand E, Jafarzadeh N, Farrokhi F, Kamalidehghan B, Houshmand $\mathrm{M}$. Is Bax/Bcl-2 ratio considered as a prognostic marker with age and tumor location in colorectal cancer? Iran Biomed J 2015;19:69-75.

7. Yip KW, Reed JC. Bcl-2 family proteins and cancer. Oncogene 2008;27(50):6398-406.

8. Mohan S, Abdelwahab SI, Kamalidehghan B, Syam S, May KS,
Harmal NS, et al. Involvement of NF-?B and Bcl2/Bax signaling pathways in the apoptosis of MCF7 cells induced by a xanthone compound Pyranocycloartobiloxanthone A. Phytomedicine 2012;19(11):1007-15.

9. Hector S, Prehn JH. Apoptosis signaling proteins as prognostic biomarkers in colorectal cancer: A review. Biochim Biophys Acta 2009;1795(2):117-29.

10. Kobayashi T, Sawa H, Morikawa J, Zhang W, Shiku H. Bax induction activates apoptotic cascade via mitochondria cytochrome $\mathrm{c}$ release and Bax of the expression enhances apoptosis induced by chemotherapeutic agents in DLD-1 colon cancer cells. Jpn J Cancer Res 2000;91:1264-8.

11. Goh SH, Chuah CH, Mok JS, Soepadmo E. Malaysian Medicinal Plants for the Treatment of Cardiovascular Diseases. Malayasia: Pelanduk; 1995.

12. Abas F, Lajis NH, Israf DA, Khozirah S, Kalsom YU. Antioxidan and nitric oxide inhibition activities of selected Malay traditional vegetables. Food Chem 2004;95:566-73.

13. Chauhan JB, Kapfo W, Jayarama S, Balaji KS. Antiangiogenic and proapoptotic activity of Averrhoa carambola L. Fruit extract on Ehrlich ascites carcinoma treated mice. Int J Appl Biol Pharm Technol 2015;6:246-54

14. Kumar CA, Jayarama S, Basappa, Salimath BP, Rangappa KS. Proapoptotic activity of imidazole derivatives mediated by up-regulation of Bax and activation of CAD in Ehrlich ascites tumor cells. Invest New Drugs 2007;25:343-50.

15. Gupta M, Mazumder UK, Rath N, Mukhopadhyay DK. Antitumor activity of methanolic extract of Cassia fistula $\mathrm{L}$. seed against Ehrlich ascites carcinoma. J Ethnopharmacol 2000;72(1-2):151-6.

16. D'Armour FE, Blood FR, Belden DA. The Manual for Laboratory Work in Mammalian Physiology. $3^{\text {rd }}$ ed. Chicago, IL, USA: The University of Chicago Press; 1965

17. Osawa T, Kawakishi S, Namiki M. Antimutagenesis and Anticarcinogenesis Mechanism II. New York: Plenum; 1990. p. 139.

18. Chauhan JB, Kapfo W. Effect of traditional sun - Drying on phenolic antioxidants of Averrhoa bilimbi L. Int J Appl Biol Pharm Technol 2013;4:26-34.

19. Aggarwal S, Gupta S. Increased apoptosis of T cell subsets in aging humans: Altered expression of Fas (CD95), Fas ligand, Bcl-2, and Bax. J Immunol 1998;160(4):1627-37.

20. Denicourt C, Dowdy SF. Medicine targeting apoptotic pathways in cancer cells. Science 2004;306:1411.

21. Ozaslan M, Karagoz ID, Kilic IH, Guldur ME. Ehrlich ascites carcinoma. Afr J Biotechnol 2011;10:2375-8.

22. Prasad B, Giri A. Antitumor effect of cisplatin against murine ascites Dalton's lymphoma. Indian J Exp Biol 1994;32(3):155-62.

23. Lin $\mathrm{HH}$, Chen JH, Huang CC, Wang CJ. Apoptotic effect of 3,4-dihydroxybenzoic acid on human gastric carcinoma cells involving JNK/p38 MAPK signaling activation. Int $\mathrm{J}$ Cancer 2007;120(11):2306-16.

24. Darzynkiewicz Z. Critical aspects in analysis of cellular DNA content. Curr Protoc Cytom 2010; Chapter 7:Unit7.2.

25. Yamaguchi H, Bhalla K, Wang HG. Bax plays a pivotal role in thapsigargin-induced apoptosis of human colon cancer HCT116 cells by controlling Smac/Diablo and Omi/HtrA2 release from mitochondria. Cancer Res 2003;63(7):1483-9.

26. El-Aziz AF, Hefni ME, Shalaby AM. Inhibitory effects of Rosemary (Rosmarinus officinalis L.) on Ehrlich ascites carcinoma in mice. Int J Curr Res Acad Rev 2014;2:330-57.

27. Kakkar S, Bais S. A review on protocatechuic acid and its pharmacological potential. ISRN Pharmacol 2014;2014:Article ID: 952943, 1-9.

28. Tseng TH, Kao TW, Chu CY, Chou FP, Lin WL, Wang CJ. Induction of apoptosis by hibiscus protocatechuic acid in human leukemia cells via reduction of retinoblastoma (RB) phosphorylation and Bcl-2 expression. Biochem Pharmacol 2000;60(3):307-15.

29. Tor YS, Yazan LS, Foo JB, Wibowo A, Ismail N, Cheah YK, et al. Induction of apoptosis in MCF-7 cells via oxidative stress generation, mitochondria-dependent and caspase-independent pathway by ethyl acetate extract of Dillenia suffruticosa and its chemical profile. PLoS One 2015;10(6): 0127441.

30. Yin MC, Lin CC, Wu HC, Tsao SM, Hsu CK. Apoptotic effects of protocatechuic acid in human breast, lung, liver, cervix, and prostrate cancer cells: Potential mechanisms of action. J Agric Food Chem 2009;57(14):6468-73

31. Tanaka T, Tanaka T, Tanala M. Potential cancer chemopreventive activity of protocatechuic acid. J Exp Clin Med 2011;3(1):27-33. 